\title{
The Implementation of Life-Review Intervention to Increase the Quality of Life on Elderly Widows
}

\author{
Venty Ratnasari Telaumbanua ${ }^{1}$, Srisiuni Sugoto ${ }^{2 *}$ \\ ${ }^{1}$ Faculty of Psychology, University of Surabaya, Indonesia \\ ${ }^{2}$ Faculty of Psychology, University of Surabaya, Indonesia \\ *Corresponding author. Email: srisiuni@staff.ubaya.ac.id
}

\begin{abstract}
Quality of Life is the viewpoint or perspective of individuals regarding how good their currently experienced life is. In later adulthood (old age), there are many changes, such as changes in physical and cognitive abilities, and also changes in social roles and emotional conditions, especially on elderly women whose husband or spouse had passed away. This condition can affect the Quality of Life of such individuals. The goal of this research was implementing the Life-Review Intervention, which was reviewing the individuals' experiences since childhood to late adulthood using the recall, reassess, reevaluate, and reintegrate processes to increase the Quality of Life of the participants. The participants in this research were two elderly widows of 54 and 63 years of age, living in East Java, who had been widows for around two years. The research method used was experimental research with single case A-B-A design, with the Quality of Life measured using the World Health Organization Quality of Life (WHOQOL-BREF) questionnaire as the main data, alongside interview and observation as the supportive data. Assessment results showed the participants having the typically negative Quality of Life on physical and psychological aspects while having the typically positive Quality of Life on social and environmental aspects. Interventions results showed that Life-Review Intervention guided individuals to reflect on their life experiences by remembering positive experiences and viewing negative experiences from different perspectives. As the result, the two participants were able to increase their physical and psychological quality, though the social and environmental aspects tended to be stable.
\end{abstract}

Keywords: Elderly Widows, Life-Review Intervention, Quality of Life.

\section{INTRODUCTION}

The elderly are people over 60 years of age [1]. In 2100 , the number of elderly people in Indonesia increased, compared to $0-14$ years of age individuals, being $41 \%: 15.7 \%$ respectively. The elderly population in Indonesia was predicted to increase even higher compared to the elderly world population after 2100 [2]. The increase in elders in Indonesia could be related to the Quality of Life increase or improvement. According to the World Health Organization Quality of Life Group (WHOQOL Group, Quality of Life is the viewpoint of the perspective of individuals regarding their position in life, in the context of culture and life values, in relation to goals, hopes, standards, and problems [3]. Quality of Life as the availability of resources required to fulfil the needs, wants, and hopes of individuals, participation in activities for personal growth and self-actualization, and preferably satisfactory comparison to others [4][5].

There are several important aspects in Quality of Life, which are: (1) physical health (physical domain/aspect), consisting of the ability to do daily activities, dependence to medicine and medical treatment, energy and fatigue levels, mobility, pain and discomfort, sleep and rest, and work capacity; (2) psychological aspect (psychological domain), consisting of body image and appearance, negative and positive feelings, self-worth, spirituality, cognitive, learning, memory, and concentration abilities; (3) social relationships, consisting of personal relationships, social life, and sexual activities; (4) environmental, consisting of source of income, freedom, physical safety and securement of health and social facilities (accessibility and quality), home environment, opportunity to obtain information 
and new skills, participation and opportunity for recreation and exercise or sports, physical environment (pollution/noise/traffic/climate), and transportation [6].

Previous study on 88 elders in Jatinangor, West Java, it was shown that most respondents had low QoL scores $(\leqslant 60)$ [7]. The results determined that $100 \%$ of respondents had low physical domain score, 98.9\% respondents had low psychological domain score, $96.6 \%$ respondents had low social relationship domain score, and $89.8 \%$ respondents had a low environmental domain. Different research on 106 participants in Surabaya as an elderly-friendly city. Surabaya was able to fulfil several components to be determined as an elderly-friendly city [8]. In reality, not all elders have "high" Quality of Life, especially experienced by A and D, both widows. A since May 2018 and D since November 2018. Both were retired teachers, showing interest in guidance in increasing their Quality of Life.

Several of the previous researches found that Life Review could increase life satisfaction, self-worth, spiritual well-being, psychological well-being, Quality of Life, while reducing depression and feelings of helplessness [9]. Life Review could increase the score of Quality of Life, support, negative emotions and life values of individuals in the interventions [10]. Life Review on elders was directly related to the coping ability, increasing environmental master and life satisfaction improvement. This research conducted a comprehensive assessment of inhibiting and supporting factors of Quality of Life, something not yet conducted by previous researches. The life Review in this research consisted of steps of the process of recalling, reevaluation, and reintegrating life experience while also facilitating the obtainment of ego integrity on the last stage of life [11]. Therefore, the goal of this research was to obtain a picture of A and D's Quality of Life, while also researching the effectiveness of Life Review intervention in increasing the Quality of Life of the participants.

\section{METHOD}

The research method in this research was a single case experiment with the A-B-A model, with 2 elders as the research participants. Both widows of less than a year retired with chronic illness and staying at home.
The research participants were determined using purposive sampling, which was the technique to choose with specific criteria as the base. A was 63 years old, with the last education of Magister in Educational Technology, currently retired, married for over 40 years, widowed since May 2018. D was 54 years old, with the last education of Bachelor's Degree in Counselling Guidance, currently retired, married for over 40 years, and widowed since November 2018.

The A-B-A design was chosen to measure the Quality of Life condition pre-intervention (A1), during the intervention (B), and post-intervention (A2). The assessment technique in the research was an observation, interview, and WHOQOL-BREF questionnaire. Questionnaire data was the main data while interview and observation data were supportive data. Data from the interview was used as support for the result. Graphical test such as HTP and DAP was also used to see the personality characteristics of the participants, with SAT projective test to see the picture of need and emotion of the participants.

In this research, Life-Review Intervention used counselling technique with the question guidelines from Life Review Experience Form (LREF) as structure stimulating the storytelling process from participants. There were 8 sessions in this research, with a total of 90 minutes for each session. The intervention consisted of 3 phases, being the initial phase, middle phase, and the final phase. The intervention process consisted of recall, reassess, reevaluate and reframe, and reintegrate (life story as a whole).

\section{RESULT}

\subsection{Trend Analysis Result}

This section of the research report explains the trend analysis results of the scale data filled by both participants. Trend analysis data consisted of 3 different phases, being the first baseline phase (A1), the treatment phase (B), and the second baseline phase (A2). Trend analysis calculation was a visual analysis in graph form, mapping the conditions of the participants on the three different phases. There are three different lines in the trend analysis graph, for the base or raw scoreline, median scoreline, and a dotted line connecting the first baseline score with the second baseline score. The effects of the intervention were determined by taking into account the 
comparison between the last position of the median line and baseline.

Table 1 shows the data of the score comparison of both participants between the first baseline, treatment, and second baseline.
The Environmental quality score of A tended to be stable, not showing significant changes during treatment and post-treatment. The baseline and median were also in one straight line, showing that life-review intervention was not effective in increasing the environmental quality of the participant.

The base score of D's Physical Quality aspect increased during the first baseline phase to the treatment phase, stabilizing on the second baseline

Table 1. Comparison of Participants' Quality of Life Score Data

\begin{tabular}{|c|c|c|c|c|c|c|c|c|c|}
\hline \multirow[b]{2}{*}{ Aspect } & \multicolumn{9}{|l|}{ Score } \\
\hline & $\begin{array}{l}\text { Base- } \\
\text { line } 1\end{array}$ & $\begin{array}{l}\text { Base- } \\
\text { line } 1\end{array}$ & $\begin{array}{l}\text { Base- } \\
\text { line } 1\end{array}$ & $\begin{array}{l}\text { Treat- } \\
\text { ment }\end{array}$ & $\begin{array}{l}\text { Treat- } \\
\text { ment }\end{array}$ & $\begin{array}{l}\text { Treat- } \\
\text { ment }\end{array}$ & $\begin{array}{l}\text { Base- } \\
\text { line } 2\end{array}$ & $\begin{array}{l}\text { Base- } \\
\text { line } 2\end{array}$ & $\begin{array}{l}\text { Base- } \\
\text { line } 2\end{array}$ \\
\hline \multicolumn{10}{|l|}{$\mathbf{A}$} \\
\hline Physical & 31 & 38 & 38 & 50 & 50 & 44 & 56 & 50 & 56 \\
\hline Psychological & 44 & 38 & 38 & 63 & 56 & 50 & 56 & 56 & 50 \\
\hline Social & 50 & 56 & 50 & 50 & 56 & 50 & 50 & 50 & 50 \\
\hline Environmental & 63 & 50 & 63 & 63 & 63 & 50 & 63 & 63 & 63 \\
\hline \multicolumn{10}{|l|}{ D } \\
\hline Physical & 38 & 38 & 38 & 44 & 44 & 56 & 50 & 56 & 50 \\
\hline Psychological & 31 & 38 & 31 & 44 & 44 & 50 & 44 & 50 & 44 \\
\hline Social & 69 & 50 & 69 & 75 & 50 & 75 & 50 & 50 & 50 \\
\hline Environmental & 56 & 50 & 56 & 63 & 63 & 63 & 56 & 63 & 63 \\
\hline
\end{tabular}

The base score of A's Physical Quality aspect increased on the first baseline phase to the treatment phase and becomes relatively stable on the second baseline phase. There was also an increase in the median on-treatment phase and second baseline phase. This indicated increase in physical quality after the Life-Review Intervention, therefore LifeReview Intervention was quite effective in increasing the physical quality of $\mathrm{A}$.

There is fluctuation in the Psychological Quality aspect of A. Participant's Psychological Quality score increased at first and then decreased at the end of the intervention. On the second baseline, the score increased again and then became stable. It is also shown that the median tended to increase and then become stable, meaning that Life-Review Intervention was quite effective to increase the participant' psychological quality.

A's Social Quality score tended to be stable, not showing significant changes during treatment and post-treatment. It also shows that the baseline and median are in one straight line, showing that LifeReview Intervention was not effective in increasing the participant's Social Quality. phase. It also shows an increase in the median on treatment and the second baseline phase. This indicated increase in physical quality after the LifeReview Intervention, therefore it was effective in increasing the Physical Quality of the participants.

There is fluctuation in the Psychological Quality of D. The score increased and stabilized to the end of the intervention. The median tended to increase and stabilize on the second baseline, showing that LifeReview Intervention was effective in increasing the Psychological Quality of the participants.

The Social Quality score of D fluctuated significantly. There was a significant chance from time-to-time, becoming stable in the second baseline. Median showed that there was a decrease in Social Quality. This showed that Life-Review Intervention was not significantly effective in increasing social quality of D.

The Environmental Quality score of D increased during treatment and then stabilized until the second baseline. It is shown that Life-Review Intervention was not significantly effective in increasing Environmental Quality of D. 


\subsection{Discussion}

In general, Life-Review Intervention given to both participants increased Quality of Life, especially in physical and psychological quality. Results of trend analysis found that both participants experienced an improvement in physical and psychological quality, during the intervention and follow up.

On the physical aspect, it was found that both participants experienced quality improvement. Data showed that Life-Review Intervention affected the physical aspect increase in both participants' Quality of Life. as psychological intervention, the effect of Life Review focused on how individuals were able to feel empowered with their current physical prowess while also making peace with the decrease in physical abilities at their current age. with LifeReview, individuals understand that weakness experienced on their current age was results of their behaviour during previous development phases. this caused individuals to stop considering old age as a weakness or as a time for them to be weak. Psychoeducation in the Life Review Intervention also helped participants to further recognize their current developmental phase. this strengthened the effect of Life Review, in understanding that their current condition is normal, as it is experienced by everyone in their old age, minimalizing the feelings of helplessness and supporting individuals to do what they wish for, even with lower physical abilities.

Knowledge of changes during old age provides individuals with an awareness of their own condition, realizing that they are not alone as everyone in the world in their old age experience it similarly. this changes individuals' viewpoint about self-image, initially viewed as weak into a more natural picture, improving acceptance. from the story of both participants, it was shown that both saw their physical condition as better, compared to others with chronic conditions. This improved their vigour and self-worth, enabling them to value their physical abilities more positively. this was supported previous study, stated that individuals experiencing life-review intervention tend to report better physical abilities (for daily living) after the intervention [10].

In the psychological aspect, both participants also showed a score increase. Data showed that Life Review Intervention had the effect of increasing psychological quality of both participants.
Psychologically positive results of Life Review can be caused by Life Review proving an opportunity to participants to state and reevaluate negative feelings and growing positive thoughts from the reintegration process [12]. Life Review also prompted individuals to reintegrate their life chronology from stories and learning from the past, especially the coping strategy used in similar problems, in order to better understand the experienced problem, stimulating the individuals to use the same coping strategy.

The problems on both participants could be seen as on the psychological aspect, especially related to the loss of a spouse. Both participants were requested to remember their family condition during childhood, and that reminded them of the moment they lost their fathers. Both participants saw that their mothers continued to strive for family life, focusing more on children. The life experience of both participants inspired them to become like their mothers. This comparison helped both participants in learning to face the problem related to the feeling of loss after the passing of their spouses.

On the social aspect, both participants showed a stable tendency. Data showed that the social quality of both participants was non-problematic. This was caused by both participants received strong social support from their neighbours. friends in their peer group, community, and also family support. The feeling of satisfaction on social support affected their quality of life, increasing it [13].

In D's case, there was a decrease in social quality after follow-up. Based on interview results, it was explained that $\mathrm{D}$ was experiencing financial problems, resulting in the participant trying to avoid several regular social meetings. This was related to the bill D needed to pay, causing worry that she would be asked for payment as it was past the deadline. The decrease could also be caused by the follow-up timing which tended to be short, therefore unable to fully see whether the participants' problems were truly solved or not, in seeing the effect of Life Review Intervention. This was a situational factor which could affect the social quality condition of $\mathrm{D}$.

On the environmental aspect, both participants also shoved stable tendencies. Data showed that for both participants since the start of the assessment, there was no significant problem in the environmental aspect. Both had average quality in freedom, security, satisfaction on the home environment, recreational opportunities, sports, and 
transportation. The home environment was related to psychological and social satisfaction [14]. This was the social capital of an individual to associate in a specific group, in their relationships with others.

Qualitative results of both participants showed data that both realized their lack of gratitude, prompting them to try aiming for self-acceptance by acknowledging and being grateful to what they had experienced. Being grateful is a positive attitude. Positive attitude helped in reaching the good quality of life [15]. In order to manage the feeling of wellbeing, it was important for elders to accept, adapt, and process life changes related to ageing, such as retirement, slowing down, decrease of health status (including that of spouse's), and losing loved ones. The inability to adapt could cause sadness and despair.

The other uniqueness of both participants in this research was that both had a strong faith in their respective religions. Both were religiously devout, conducting in religious activities and rituals such as praying, donating, and being active in religious services. Being religious or spiritual could support elderly individuals in accepting psychological pressure, in managing chance and life satisfaction [15]. Religion and spiritual belief formed individuals' life philosophy and could also reduce distress regarding life. Several elders relied on God and used God as a beacon to help with life problems. Faith provided individuals with comfort, peace of mind, and also feeling of valuing life and life goals, prompting them to hope for good each day. Becoming a volunteer and joining religious activities and practices were pictures as a method to say active socially. Life-Review could increase spiritual wellbeing [16].

From the story of both participants, it was found that most emotions from the past, in each developmental phase, were more positive than negative. While both participants also emphasized that the developmental phase they considered to be discomforting was their current elderly developmental phase. In this case, Life Review had the role in making individuals realize that their current developmental phase was the phase which changes were mostly of decrease inability. In the current condition of discomfort, Life Review helped individuals in seeing positive experience, so individuals could still find positives aspects in their selves.
Life-Review asked individuals to reassess various accomplishments in their past, making it so individuals could gradually see themselves positively [17]. Positive thoughts regarding the self were a significant mediator affecting anxiety and depression symptom level [18]. This indicated that with positive thoughts resulted from life review could help reduce anxiety and depression symptom levels. Life-Review had a significant effect on emotional and psychological well-being [19]. This was because Life Review helped in minimalizing negative thoughts through the reevaluate process by finding new meaning for experienced negative incidents, and also increasing positive thinking with the recall process.

Expressing negative emotions was a strategy to make peace with negative feelings [20]. Through Life-Review process, individuals were asked to recall their whole life process and reflect on their past experiences, including good experiences and overcoming conflicts in feelings and emotions by providing new meaning on experiences considered to be uncomfortable or bad by the individuals. Providing new meaning means asking the participants to view the incident through a different perspective, preferably one which could be accepted by the individuals.

Rediscovering positive experiences would rejuvenate positive thoughts and balance regarding the current negative thoughts, resulting in individuals feeling better about their situation [9]. Making peace with negative experiences can also reduce negative thoughts, as reconciliation provided individuals to let go, accept, or give new meaning on the negative experience.

\subsection{Conclusion and recommendations}

Based on the process starting assessment to intervention, there were several conclusions, as follows: (1) Participants experienced problems in the quality of life in the physical aspect, being an adaptation problem with the decrease of physical abilities and current illness; and the psychological aspect in sadness from losing a spouse; (2) LifeReview Intervention supported the increase of physical quality of both participants by providing psychoeducation to participants regarding experienced chance in old age, and increasing feeling of empowerment in the current condition; (3) LifeReview Intervention increased the psychological quality of both participants by reevaluating every 
uncomfortable life experience and finding a new perspective on those experiences, while also increasing positive thoughts with gratitude; (4) LifeReview process helped participants recall their whole life process and reflecting the past experiences including the comfortable experiences and finding a different viewpoint for uncomfortable to obtain a new understanding for those experiences.

Based on research results and evaluation on research limitations, there are several suggestions for future researches: (1) The storytelling technique used in the intervention could be further improved other than just the Life-Review Experience Form (LREF) to encourage participants for more comprehensive stories by using materials such as photographs; (2) Future researchers should avoid conducting continuous follow-up (giving significant gap between each measurements) to minimalize situational factors; (3) Future researchers should conduct more intensive guidance and add more applicative activities for LifeReview as a form of independent action for the participants to do even post-intervention; (4) Both research participants were widows so there is a need to apply the research on windows to test the effectiveness of Life-Review intervention; (5) Lifereview intervention could be conducted on individuals in retirement homes to help individuals become more independent with better quality of life.

Also there are several suggestions for participants: (1) Participants should continue the intervention by writing as an independent process, also to enable rereading the writing to reduce memory loss tendencies in old age; (2) Participants should strive to find different perspective on every uncomfortable experience in life; (3) Participants should have self-openness regarding their life experiences as a base for self-awareness on their own experiences and to be able to focus in facing it.

\section{AUTHORS' CONTRIBUTIONS}

VRT created the idea for the study, drafted and edited the manuscript, analyzed the data, compiled the data, tables in the manuscript. SS as the co-author interpreted the result, oversaw the study, created the idea for the study, and guided the writing of the manuscript. All authors have read and approved of the manuscript.

\section{ACKNOWLEDGMENTS}

The study was supported by 2020 Faculty of Psychology, University of Surabaya.

\section{REFERENCES}

[1] National Regulation Number 13 the Year 1998 (Undang-Undang Nomor 13 Tahun 1998) regarding Elderly Health.

[2] Indonesia Ministry of Health. Situasi Lanjut Usia (Lansia) di Indonesia. 29 Mei - Hari Lanjut Usia Nasional. 2016. Jakarta: Pusat Data dan Informasi.

[3] L. Paskulin, A. Molzahn. Quality of life of olfer adults in Canada and Brazil. West. J. Nurs. Res. 29(1) (2007) 10-26.

[4] A. Walker. A European Perspective on Quality of Life in Old Age. Eur. J. Ageing 2(1) (2005) $2-12$

[5] P. Theofilou. Quality of life: Definition and measurement. Eur. J. Psychol. 9(1) (2013) 150162.

[6] World Health Organization (WHO). WHOQOLBREF: Introduction, Administration, Scoring and Generic Version of The Assesment. Geneva: Alison Harper; c1996.

[7] A. Hidayati, S. Gondodiputro, L. Rahmiati. Elderly Profile of Quality of Life Using WHOQOL-BREF. Althea Med. J. 5(2) (2018) $105-110$.

[8] J. Pudjibudojo, S. Wahyuningsih, Setiasih, S. Sugoto, T. Rahardjo. Surabaya: Kota ramah lanjut usia. Project Report. Fakultas Psikologi Universitas Surabaya dan Pusat Kelanjutusiaan Universitas Indonesia, Surabaya; 2013.

[9] H. Xiao, E. Kwong, S. Pang, E. Mok. Effect of life review program for Chinese patients with advanced cancer: A randomized controlled trial. Cancer Nursing 36(4) (2013) 274-283.

[10] R. Wren. Effect of life review on quality of life for older adults living in nursing homes. Phys. Occup. Ther. Geriatr. (2017) 1-20.

[11] J. Feist, G. Feist. Teori kepribadian. Jakarta: Salemba Humanika; c2010. 
[12] X. Zhang, H. Xiao, Y. Chen. Effects of lifereview on mental health and well-being among cancer patients: A systematic review. Int. J. Nurs. Stud. 74 (2017) 138-148.

[13] M. LaRocca, F. Scogin. The effect of social support on quality of life in older adults receiving cognitive behavioral therapy. Clin. Gerontol. 38(2) (2015) 131-148.

[14] R. Gobben, M. Assen. Associations of environmental factors with quality of life in older adults. The Gerontologist (2017) 1-10.

[15] K. Leeuwen, M. Loon, F. Nes, J. Bosmans, H. Vet, J. Ket, G. Widdershoven, R. Ostelo. What does quality of life mean to older adults?: A thematic synthesis. PLoS ONE 14(3) (2019) 139.

[16] M. Ando, T. Morita, T. Okamoto, Y. Ninosaka. One-week short-term life review interview can improve spritual well-being of terminally ill cancer patients. Psychooncology 17 (2008) 885890.

[17] H. Hanaoka, H. Okamura. Study on effects of life-review activities on the quality of life of the elderly. A randomized controlled trial. Psychoter Psychosom. 73 (2004) 302-311.

[18] J. Korte, G. Westerhof, E. Bohlmeijer. Mediating processes in an effective life-review intervention. Psychol Aging. 27(4) (2012) 11721181

[19] S. Lamers, E. Bohlmeijer, J. Korte, G. Westerhof. The efficacy of life-review as onlineguided self-help for adults: a randomized trial. J. Gerontol B. Psychol Sci Soc Sci. 70(1) (2015) 24-34.

[20] K. Niederhoffer, J. Pennebaker. Sharing one's story: On the benefits of writing or talking about emotional experience. Oxford University: New York; c2009. 